\title{
The Reproduction of the Red Sea Coral Stylophora pistillata. I. Gonads and Planulae
}

\author{
B. Rinkevich and Y. Loya \\ Department of Zoology, The George S. Wise Center for Life Sciences, Tel Aviv University, Tel Aviv, Israel
}

\begin{abstract}
The reproduction of Stylophora pistillata, one of the most abundant coral species in the Gulf of Eilat, Red Sea, was studied over more than two years. Gonads were regularly examined using histological sections and the planula-larvae were collected in situ with plankton nets. S. pistillata is an hermaphroditic species. Ovaries and testes are situated in the same polyp, scattered between and beneath the septa and attached to them by stalks. Egg development starts in July preceding the spermaria, which start to develop only in October. A description is given on the male and female gonads, their structure and developmental processes. During oogenesis most of the oocytes are absorbed and usually only one oocyte remains in each gonad. $S$. pistillata broods its eggs to the planula stage. Planulae are shed after sunset and during the night. After spawning, the planula swims actively and changes its shape frequently. A mature planula larva of S. pistillata has 6 pairs of complete mesenteries (Halcampoides stage). However, a wide variability in developmental stages exists in newly shed planulae. The oral pole of the planula shows green fluorescence. Unique organs ('filaments' and 'nodules') are found on the surface of the planula; these might serve as attachment organs. A hypothesis is offered for further examination suggesting a trend of brooding versus non-brooding species in scleractinian corals: Coral species which develop gonads in their body cavities (usually branching forms or small polyped corals) reduce the number of eggs during oogenesis, have small eggs and brood planula-larvae, while coral species which develop gonads within their mesenteries (usually massive growth forms or large polyped corals) have numerous and large ova per polyp and expel their eggs into the water.
\end{abstract}

\section{INTRODUCTION}

There are many gaps in our knowledge of the biology of scleractinian corals, especially in regard to their sexual reproduction. A significant portion of the research on corals deals with their community structure, growth rates, calcification processes, nutrition and their role in reef formation. Most of the studies on coral reproduction were performed in the beginning of this century and during the Great Barrier Reef Expedition (1928-1929). Recently, Stimson $(1976,1978)$ reported on the mode and timing of reproduction in some common hermatypic corals of Hawaii and Enewetak.

Approximately 100 scleractinian coral species are known from the Gulf of Eilat, Red Sea (Loya and Slobodkin, 1971). Very little is known about their biology and so far almost nothing about their reproduction. Detailed knowledge of coral reproduction may elucidate some aspects of their life history strategies (Loya, 1976a), possible perturbations caused by man (Rinkevich and Loya, 1977), and a better understanding of the coral reef as a whole.

Stylophora pistillata (Esper) is one of the most abundant coral species in the Gulf of Eilat. It is dominant in the lagoon, rear-reef and reef-flats, and abundant in the fore-reef (Loya and Slobodkin, 1971; Loya, 1972). This species has a branching growth form. Each branch consists of numerous minute polyps, about $0.8 \mathrm{~mm}$ in diameter. Colours of living colonies range from darkbrown, purple, brownish-yellow to pale-pink. This species is characterised by a rapid growth rate (Loya, 1976a), high recruitment (Loya 1976b) and rapid regeneration rate (Loya , 1976c). S. pistillata forms a substrate and habitat for many species of crabs (mainly Xanthidae and Alpheidae), fishes (especially Pomacentridae and Gobiidae), as well as a rich fauna of cryptic organisms such as sponges, bivalves, polychaetes and others. The knowledge of the life history of $S$. pistillata may thus enhance a better understanding of the complex, interspecific relationships of the animal community structure accompanying this species.

Marshall and Stephenson (1933) claimed that the problem of studying reproduction in corals can be approached from two points of view: Since some of the corals are viviparous one may attempt to discover their breeding season by finding out at what time they liberate planulae. On the other hand, one may regularly examine their gonads in order to determine when 
they are ripe. Integration of both approaches seems to be most informative. In the present study we chose to use both histological work combined with field observations in order to study the different stages in the development of gonads and planulae in Stylophora pistillata.

\section{MATERIALS AND METHODS}

The study area is located five $\mathrm{km}$ south of the Coral Nature Reserve of Eilat, Red Sea. In this area the lagoon is about $20 \mathrm{~m}$ wide, dominated by Stylophora pistillata colonies. The reef-flat and fore-reef zones are highly diverse with coral species. The study location was visited approximately every month from March 1974 to September 1975.

Every month 6 to 14 big colonies of Stylophora pistillata (approximately $10 \mathrm{~cm}$ in their larger diameter) were randomly sampled in order to study the rate of development of their genital cells. During the study approximately 350 colonies were sampled and histologically examined. One branch was broken from each colony by a diving knife and put into a marked plastic bag. Since there is synchronization in breeding between different branches within the same colony (Rinkevich and Loya, 1979), a sampled branch represents the rate of reproduction of the whole colony. The height $(\mathrm{H})$, width (W), and length (L) of each colony were measured underwater by a plastic ruler. Since the shape of $S$. pistillata approximates a sphere, the mean geometric radius $(\bar{r})$ of each colony was calculated using the expression $\bar{r}=\left(\right.$ L. W. H.) ${ }^{1 / 3} / 2$ (see Loya, $1976 \mathrm{a}$ ). In addition, four big colonies were chosen in the beginning of this study, in order to follow the development of gonads within the same colony throughout the year. A small branch was broken from each of these colonies every month for histological sectioning.

The coral samples were fixed in $4 \%$ formalin solution in sea water for $24 \mathrm{~h}$, rinsed $1 / 2 \mathrm{~h}$ under tap water and transferred to $70 \%$ methyl-alcohol for further procedures. The preservation proved to be excellent for the purpose of the histological work. In the laboratory, decalcification was carried out in two different procedures: (1) Nitric acid treatment: Each branch was transferred into a special glass vial, containing 50 to $100 \mathrm{~cm}^{3}$ of $20 \%$ methyl-alcohol and then, nitric acid was slowly added until decalcification was completed. The remaining tissue was rinsed for a few min under tap water and transferred into $70 \%$ alcohol. This method proved to be inefficient for histological study, since quite often the nitric acid damaged the structure of the coral cells. (2) Formic acid and sodium citrate treatment: Two solutions were prepared, one of formic acid in distilled water $(1: 1)$ and the other sodium

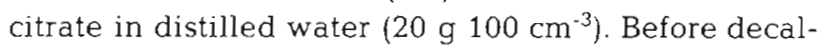
cification the two solutions were mixed (1:1) and poured into vials containing the samples. After decalcification was completed the tissue was rinsed in tap water and transferred into $70 \%$ methyl-alcohol. This method was preferred to the previous one since it was faster, easier to handle and, therefore, it is recommended for coral histological studies. A piece of tissue was taken from each branch and serial histological sections were prepared, $10 \mu \mathrm{m}$ thick, stained with Delafield hematoxyline and eosin.

Planulae were collected in situ using plankton nets (125 $\mu \mathrm{m}$ mesh). Stylophora pistillata colonies in various size groups were covered by the nets in the late afternoon and were removed at night (9 to $12 \mathrm{p}$. m.). This form of sampling took place every month for a period of approximately two years. After removal, the nets were tied underwater and transferred to the laboratory in buckets filled with sea water. The captured planulae were carefully collected, counted and observed under a disective microscope. Some of the planulae were fixed in a solution of $4 \%$ formalin and $6 \mu \mathrm{m}$ histological sections were prepared.

\section{RESULTS}

From the histological study it is concluded that Stylophora pistillata is hermaphroditic. Ova and testes are situated in the same polyp (Fig. 1:3,4) scattered between and beneath the septa. Only few colonies within the population, especially young specimens ( $\bar{r}$ less than $3.5 \mathrm{~cm}$ ), contain spermaria only (Rinkevich and Loya, 1979). However no colonies were found to contain only female gonads. Ova and spermaria develop from the mesenterial epithelium, extending into the body cavity. The gastric cavities of polyps, which were not in reproductive state were found to be empty (Fig. 1: 1). During the breeding season polyps contain a high density of genital cells, from their bases (Fig. 1: 3 ) to their upper parts, such as the pharynx (Fig. 1: 2) and tentacles (Fig. 2: 4). The gonads are attached to the mesenteries by stalks which are built of mesoglea and endoderm (Fig. 1: 4). Most of the individual polyps in a breeding colony contain several ova and spermaria (usually not more than 5 male and 5 female gonads per polyp). Egg development starts in July preceding the spermaria which start to develop only in October.

\section{Male Gonads}

When colonies are in extensive reproduction, spermaria fill up all available spaces within the polyps (Fig. 1: 2). Testes appear at the basis of the polyp, in its 
gastric cavity, and penetrate up into the middle of the tentacles (Fig. 2: 4). It is still unknown whether polyps which are filled up with gonads are capable of preying on and assimilating zooplankton.

The testes consist of sacs of various sizes and shapes (spherical, oval, elongated, strip like). It seems that testis shape is determined by the form of free space within the polyp. Each male gonad is enveloped by two layers: an outer endodermal stratum and an inner mesoglea layer. Very few zooxanthellae may be found in the endodermal layer. Each testis consists of one or more lobes, separated from one another by a layer of dense substance derived from the mesoglea of the gonad stalk. In many cases various lobes of the same testis are found in different stages of development (Fig. 2: 2) and sometimes are situated in different mesenterial cavities. Where a male gonad has two lobes, situated in separate mesenterial cavities, each lobe is enveloped by the two layers. The male gonads may reach 500 to $600 \mu \mathrm{m}$ in diameter. The strip-like gonads are the smallest in diameter and vary between 90 to $180 \mu \mathrm{m}$.

The development of a male gonad starts with a primary spermary which extends slightly from the mesentery into the cavity. Through successive divisions the primary spermary increases in size and gradually is filled up with spermatogonia. It is common to find an empty cavity within a young spermary (Fig. 2: 1) which disappears through further development and gives rise to a male gonad containing spermatids and spermatocysts. Spermatogonia are $5 \mu \mathrm{m}$ in diameter, have a spherical shape and contain a big nucleus. They are slightly eosinophilic-positive and stain dark brown. Spermatids and spermatocysts measure approximately $2 \mu \mathrm{m}$ in diameter, have a spherical shape and stain black. During further development the gonad becomes densely packed with sperm (Fig. 1: 2). After shedding sperm by a ripe spurmary a new cavity is formed in the center of the male gonad (Fig. 2: 3). In contrast to the empty cavity in the young spermary the new cavity contains some sperm. The sperm cells have long tails, distinct heads and exhibit rapid movement after liberation. They stain black by Delafield hematoxylin. Observations in the laboratory and in the field indicate that sperm-shedding occurs simultaneously from a large group of polyps, since a white cloud of sperm covered the colony during extrusion. The exact mechanism of the sperm release is still unclear
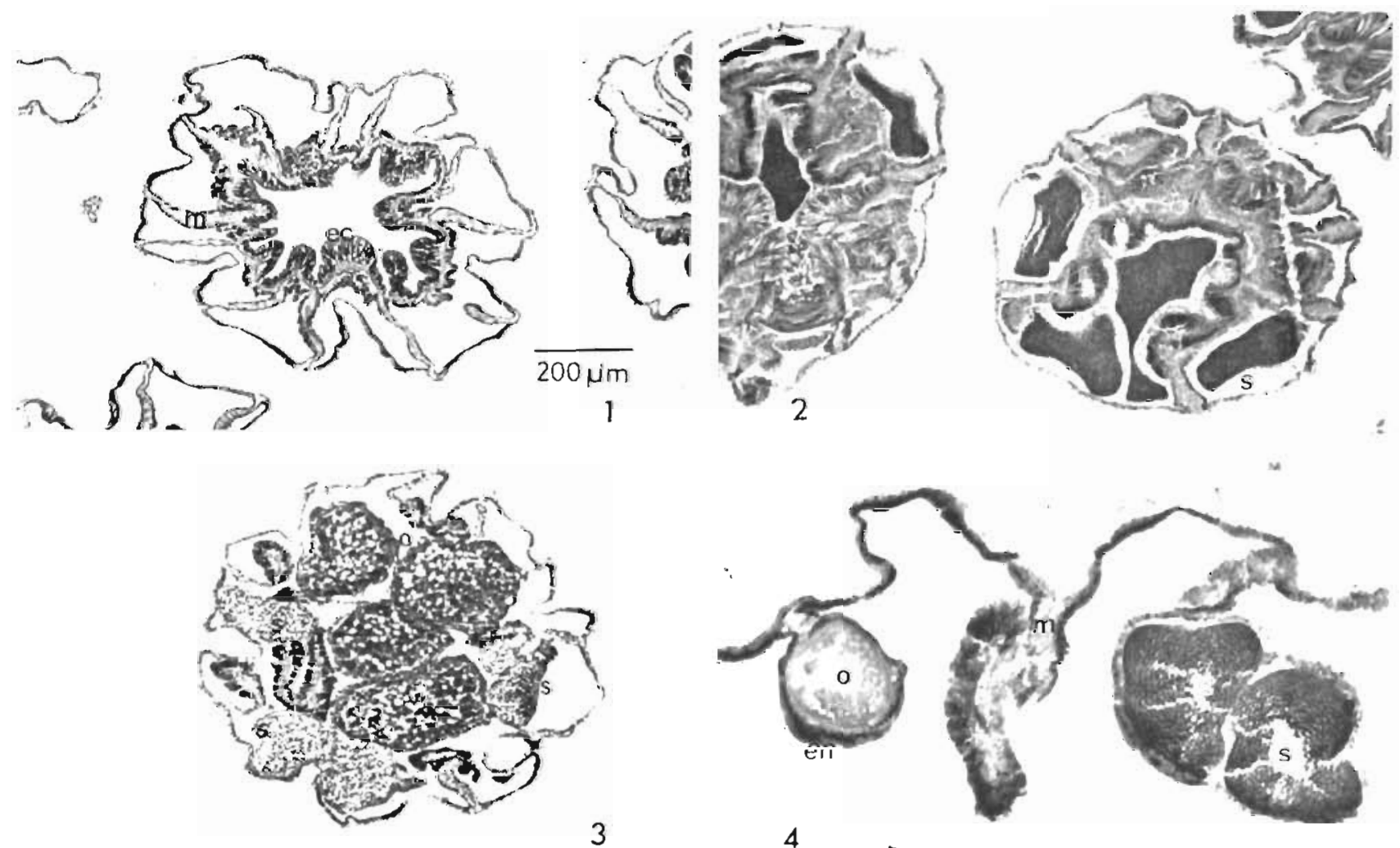

3

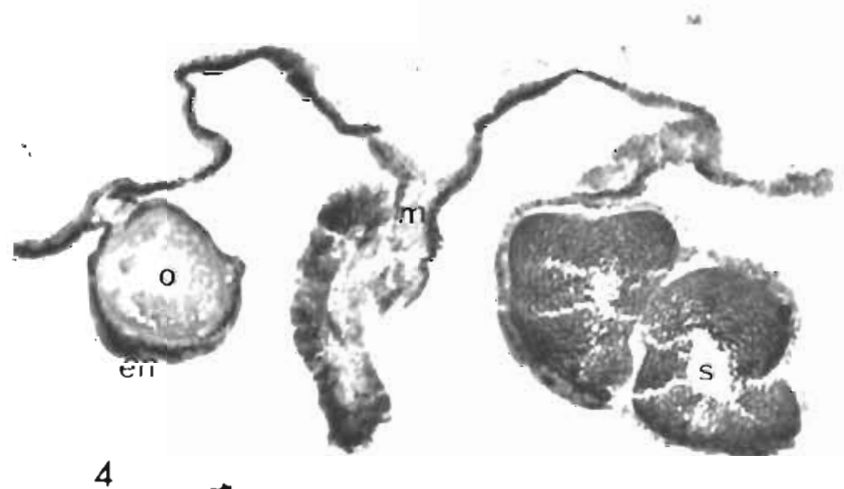

Fig. 1. Stylophora pistillata. Cross sections. 1: Mouth region of a polyp (X 70). 2: Upper parts of two polyps packed with male gonads (X 70). 3: Lower part of a polyp, intensive reproductive stage (X 70). 4: Male and female gonads attached by stalks to mesentry basis (X 140). ec: ectoderm; en: endoderm; $\mathrm{m}$ : mesoglea; o: female gonad; s: male gonads. (Scale bar $=200 \mu \mathrm{m}$ ) 

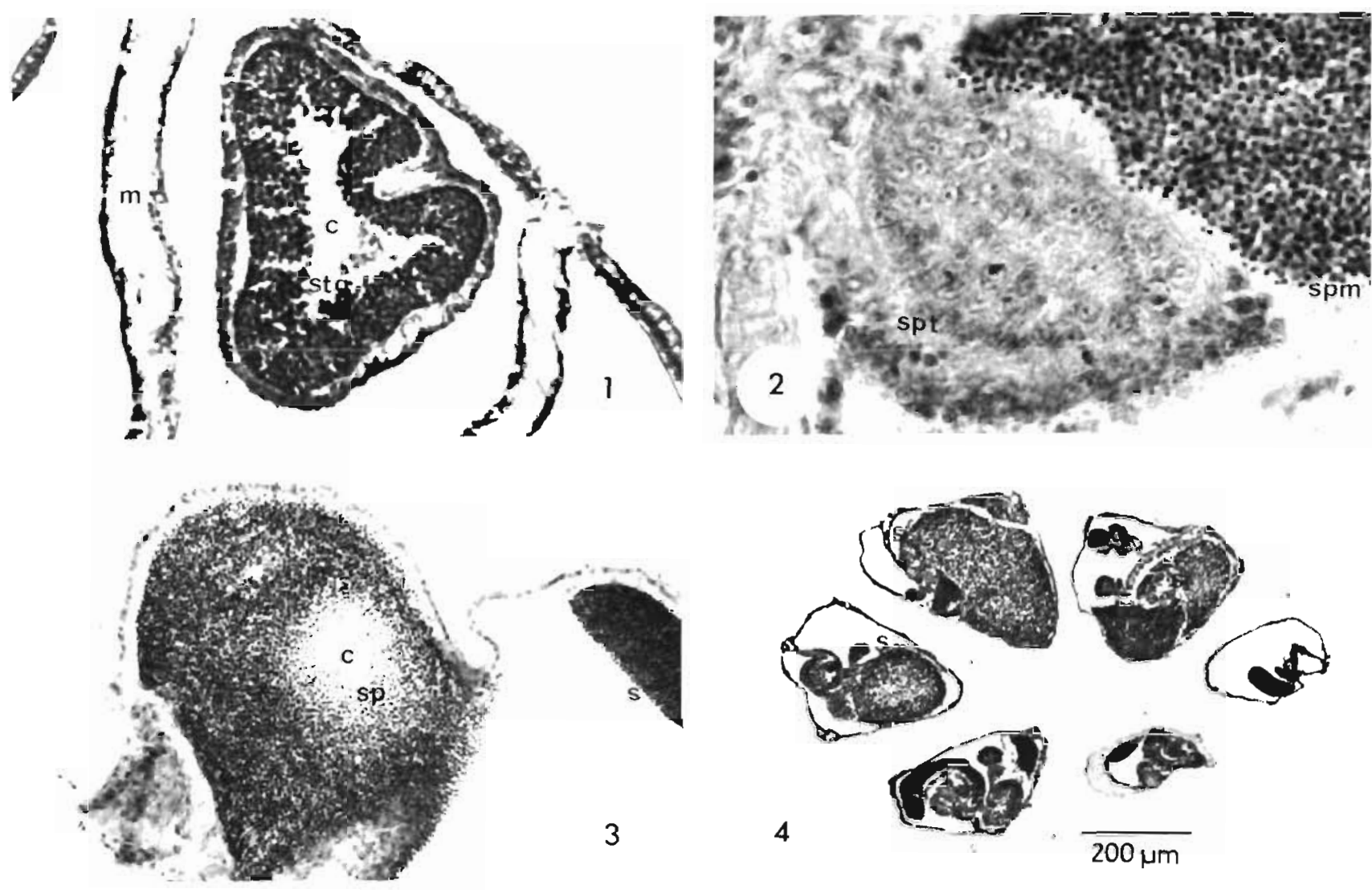

Fig. 2. Stylophora pistillata. Cross sections through male gonads. 1: Cavity within a young, male gonad (X 280). 2: Two lobes of the same male gonad, different reproductive stages $(X 700)$. 3: Cavity within a mature male gonad (X 280). 4: Tentacles containing male gonads $(X 70)$. c: cavity; $m$ : mesoglea; s: male gonad; sp: sperm; spm: spermatides; spt: spermatocytes; stg: spermatogonia

\section{Female Gonads}

Ovaria may be found in all cavities of a polyp which is in a reproductive state, they are especially concentrated in its lower parts (Fig. 1: 3). Female gonads appear sometimes up to the base of the tentacles, but never extend into the tentacles like spermaria. Similar to the male gonads, the female gonads are situated on a little stalk derived from the endoderm. The female gonad-stalk is thicker than the male gonad-stalk, due to the enlargement of the mesoglea. Like the testes, eggs are enveloped by two layers: The mesoglea layer and the endoderm. The endoderm of the eggs contains significantly more zooxanthellae than the male-gonad endoderm. In some eggs, approximately 100 zooxanthellae were found in the endoderm; the egg itself contains no zooxanthellae.

The primordial oocyte consists of a slightly granular cytoplasm with a large spherical nucleus. The oocytes are formed from primordial female cells. Each young female gonad contains 4, 8 or 16 oocytes (Fig. 3: 1). Most of the oocytes are absorbed during their growth and by the end of this process usually one big remains in each ovary (Fig. 3: 2). Sometimes two oocytes may be found in a single female gonad (Fig, 3: 5). The oocytes are spherical, ovoid, or sometimes of less regular form. Their cytoplasm is packed with little spheres which in histological sections appear as cavities (Fig. 3: 2-5). It is possible that these spheres contain lipid storage materials which melted due to histological procedures. The ooplasma is eosin positive, stains pink and is loaded with deeply stained granules. A mature oocyte is approximately $230 \mu \mathrm{m}$ in diameter, contains an oval nucleus ( $30 \mu \mathrm{m}$ in diameter) and a single spherical and granular nucleolus $(5 \mu \mathrm{m}$ in diameter), which stains red.

An immature egg contains a spherical nucleus in its center. As it matures, the nucleus migrates towards the periphery of the egg, becomes somewhat elongated, its membrane disintegrates and it gradually disappears (Fig. 3: 3, 4). At this stage the egg is ready for fertilization. Towards the end of the reproduction season, unfertilized eggs are atrophied (Fig. 3: 6) and consequentiy disappear. 


\section{Planula-Larva}

Stylophora pistillata broods its eggs to the planula stage (see below). The planulae are situated in the center gastric cavities occupying the entire space below the mouth (Fig. 4: 1). A planula consists of two epithelia, a columnar epidermis and a less regularly organized gastrodermis, separated by a thin mesoglea (Fig. 4: 1, 2). Its gastrodermis contains zooxanthellae and spherical vacuoles. The epidermis is a simple columnar epithelium, containing nematocysts and bearing cilia.

Stylophora pistillata planulae are liberated after sunset and at night. During the reproductive season 150 plankton nets, placed over adult colonies during the day and removed before sunset, yielded together only a few planulae. However, each plankton net placed over a colony during the same days (4 to 5
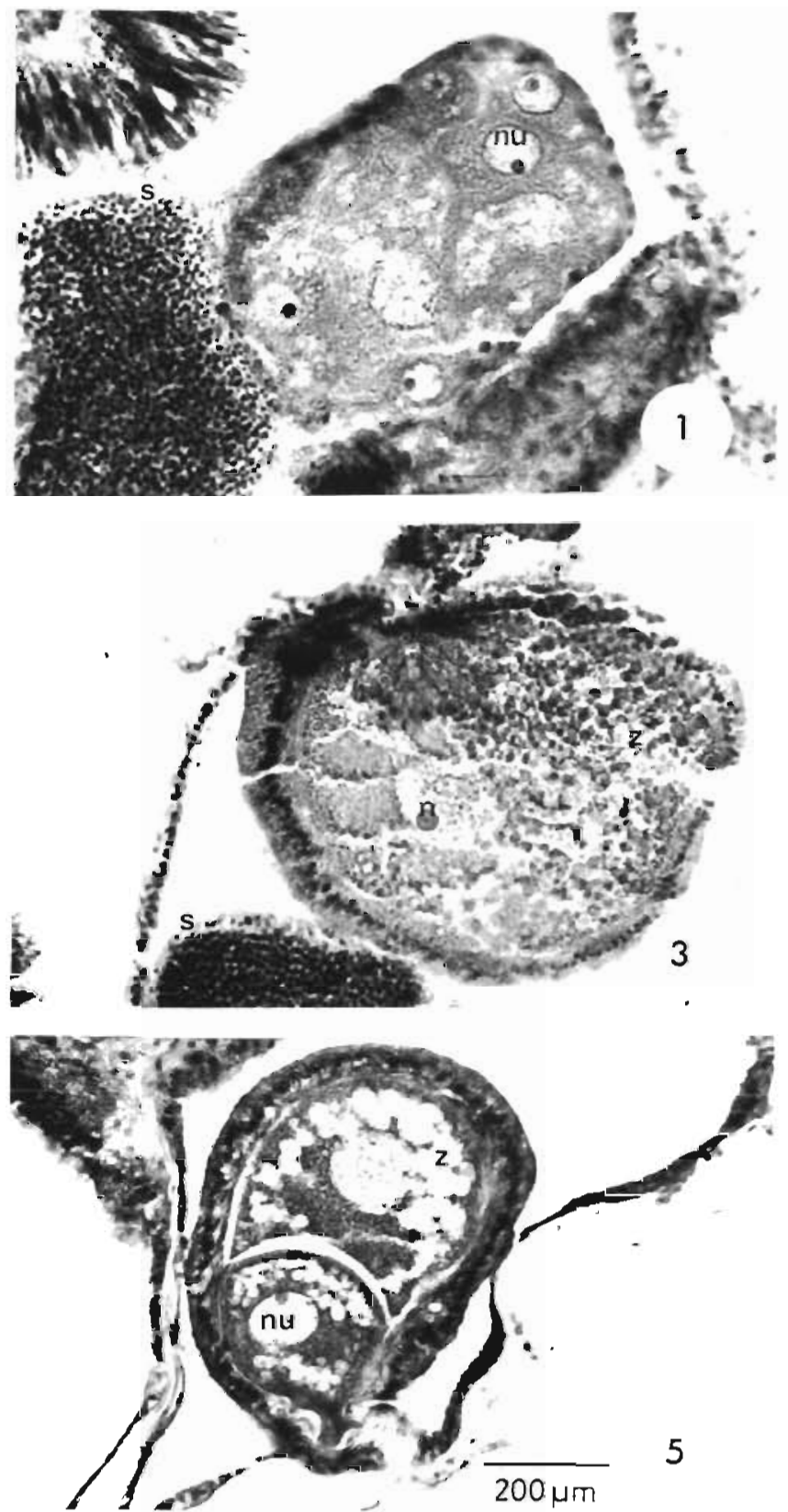
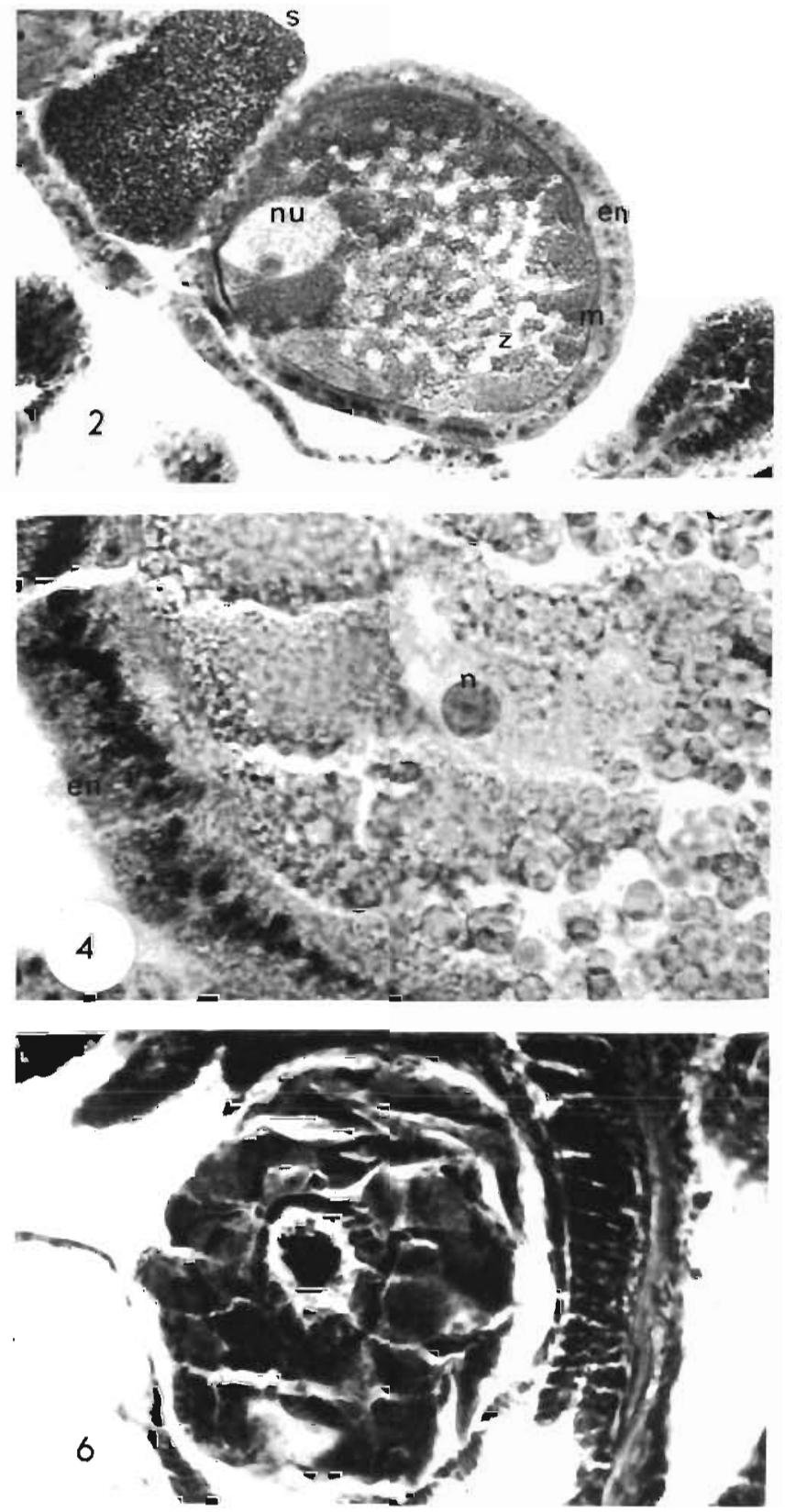

Fig. 3. Stylophora pistillata. Cross sections through female gonads. 1: Young female gonad containing 16 oocytes (X 140). 2: Adult oocyte (X 140). 3: Egg (X 140), 4: Nucleus area within an egg (X 700). 5: Example of two oocytes developing from a single female gonad (X 70). 6: Unfertilized egg in process of decomposition (X 70). en: endoderm; m: mesoglea; $n$ : nucleoli, nu: nucleus; s: male gonad; $\mathrm{z}$ : reservoir materials 


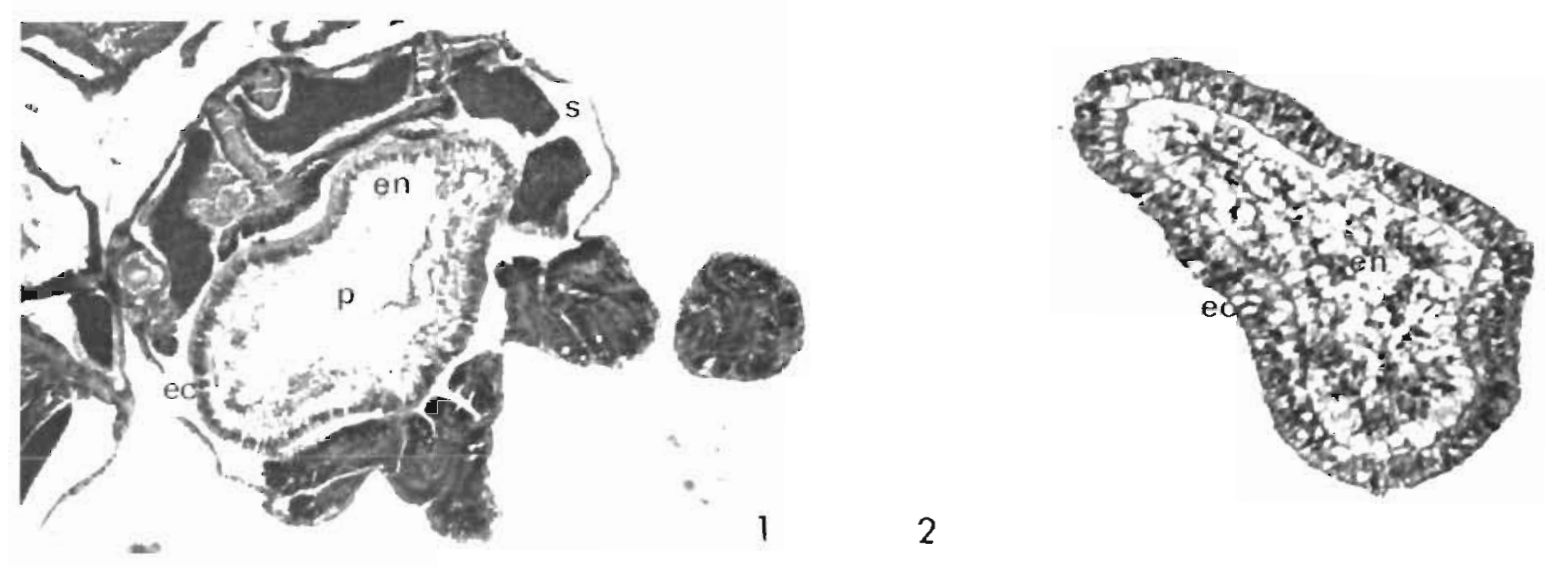

Fig. 4. Stylophora pistillata. Cross sections through planula-larva. 1: Young planula in the gastric cavity of a polyp (X 70). 2: Prematurely shed planula (X 70). ec: ectoderm; en: endoderm; p: planula; s: male gonad

p. m.), but removed at night (10 to 11 p. m.), contained large numbers of planulae, sometimes up to 400 planulae per coral head.

During shedding the planula-larvae are always spherical (Fig. 5: 1); they emerge with their oral pole first. The average size of a spherical planula is about $0.7 \mathrm{~mm}$ in diameter. Spawning takes place within a few minutes. After spawning the planula swims actively and frequently changes its shape from spherical to pear-like, disc-like and rod-like (approximately $1.0 \mathrm{~mm}$ in length; Fig. 5: 2-4). Sometimes planula larvae elongate up to $2.0 \mathrm{~mm}$ with a diameter of 0.2 $\mathrm{mm}$. Changes in the shape of a planula may occur while swimming or resting

Zooxanthellae in a planula larva are mainly concentrated in its mesenteries. When the zooxanthellae are observed against the bright background of the planula body, 12 pairs of dark lines may be seen (Fig. 5: 1-4). The oral pole of the planula is bright and shows green fluorescence when exposed to violet or ultraviolet light.

In the laboratory and under stress - such as powerful light, sudden increase in water temperature -, or sometimes without any obvious reason, planulae expel zooxanthellae, mucus and unidentified lipid-like granules from their oral pole (Fig. 5: 5). Duerden (1902) described a similar phenomenon in planula larvae of Favia fragum and cited Lacaze-Duthiers (p. 522) who illustrated the ejection of waste material in larvae of the coral Astroides. A question still remains whether the mouth of the planula of Stylophora pistillata (Fig. 5: 5, 6) functions also as a nutritive organ. Stressed planulae which were returned into aquaria with running sea water did not show any ill effects or any clear decrease in survival rate.

A mature planula larva of Stylophora pistillata has 6 pairs of complete mesenteries (Halcampoides stage). Numerous observations on just-released planulae reveal considerable variability in developmental stages: Planulae which are pale and lack complete mensenteries, and planulae with 3 or 4 pairs of complete mesenteries (Edwardsia stage or Halcampoides stage). Laboratory observations indicate that settlement of Stylophora pistillata planulae occurs only at the Halcampoides stage. It may be assumed that planulae of less advanced stages complete their development during the free swimming stage. The development from an immature planula to the Halcampoides stage usually lasts up to $30 \mathrm{~h}$ under laboratory conditions.

Stylophora pistillata planulae contain unique organs (Fig. 5: 1-4) which consist of ectodermal-mesogleal material only ('filaments') and organs which contain also endodermal epithelium ('nodules'). The filaments are elongated and of ten curl into a ring-like shape. The nodules are globular, packed with zooxanthellae, and appear granulated. The planula is capable of 'absorbing' the filaments and nodules quickly and of 'producing' new ones in different parts of its surface. These organs appear rapidly, usually in the lower part of the planula (near the aboral pole) although sometimes they also appear near the oral pole.

The activity of individual planulae differs: some planulae are very active and move in all directions; others are inactive moving slowly in one direction only; still others remain motionless. Newly born planulae tend to move rapidly or spin at one point, while older planulae tend to float to the water surface (in aquaria) or swim down and settle on the bottom. All forms of movement identified by Harrigan (1972) for Pocillopora damicornis planulae were also observed in Stylophora pistillata larvae: no run, straight swimming, swimming with dips, downward vertical swimming, upward vertical swimming, circling, stopping, spiralling, spinning, swaying and reversing.

Observations on the planktonic time of about 3,000 
Stylophora pistillata planulae conducted in laboratory aquaria indicate that in the first $48 \mathrm{~h}$ after shedding, a large number of planulae settle. After $120 \mathrm{~h}$, most of the planulae have settled. The maximum free swimming period of a planula observed in our aquaria was 35 days.
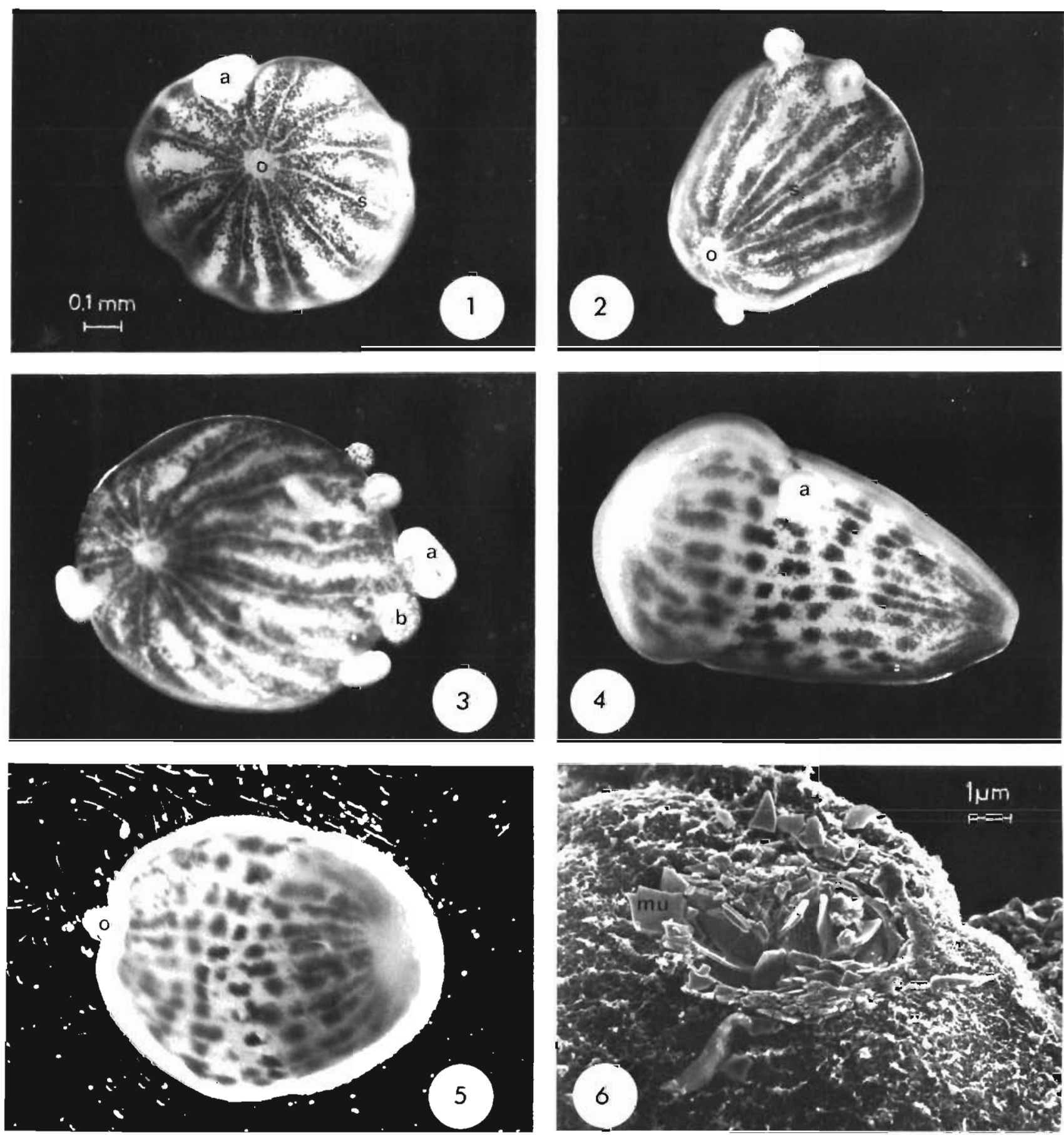

Fig. 5. Stylophora pistillata. Planula-larvae. 1-4: Different shapes of the same planula. 5: Expulsion of zooxanthellae from oral pole. 6: Scanning electron micrograph of oral pole. a: filament; b: nodule; mu: mucus sheets; o: oral pole; s: septa 
den, 1902). Only few reports on the biology of corals deal with reproduction and provide a description of genital cells (see reviews by Campbell, 1974 ; Connell, 1974), possibly because of the difficulties involved in regular colony sampling over at least one year. The vast majority of studies on coral reproduction provide information gathered within a short period.

Studies on the distribution of gonads in corals do not indicate any general trend towards a monoecious or dioecious character of the polyp. In his review, Connell (1974) concludes that Pocillopora brevicornis, Manicina areolata, Diploria labyrinthiformis, Favia fragum, Favia doreyensis and Lobophyllia sp. contain eggs and sperm at the same time in the same individual polyp, while other species, such as Acropora durvillei, A. palmata, Turbinaria sp., Sphenotrochus, rubescens, Coenopsammia sp., Isophyllia sinuosa, Montastrea cavernosa, Siderastrea radians and Symphyllia recta are unisexual containing only eggs. Only testes were found in a colony of Pavona cactus. Stimson (1976) reported that Pocillopora meandrina, $P$. damicornis and Montipora sp. contained eggs and testes in the same colony, while ovaries only were seen in Porites polyps, except in one instance in February, where polyps contained only testes.

In the present study, we have established that Stylophora pistillata is hermaphroditic. Preliminary studies of other Red Sea Corals indicate that Acropora hemprichi, Seriatopora caliendrum, Favites abdita, Favia favus and Platygyra lamellina are hermaphroditic as well (Rinkevich and Loya, unpublished data).

According to Marshall and Stephenson (1933) coral gonads are situated in the mesenteries, constituting local thickenings. Such gonad position was found by them in Favia doreyensis. We established a similar gonad position in the Red Sea massive scleractinians Favia favus and Favites abdita. However, in branching corals the gonad position seems to be different. In Stylophora pistillata, the gonads are separated from the mesenteries by short stalks and bulge into the body cavity (Fig. 1: 4; Fig. 3: 2, 5). This phenomenon was first mentioned by Fowler (1888) in Pocillopora brevicornis who noted that both ovaries and testes do not occupy the usual position in the plane of the mesenteries, but project from their sides in a manner more characteristic of certain Alcyonaria. Preliminary histological sections in other branching Red Sea species such as Acropora hemprichi, Pocillopora danae and Seriatopora caliendrum indicate a gonad structure similar to that of Stylophora pistillata.

In Stylophora pistillata we found that ova develop first (protogynous development), then the spermaria. This phenomenon was mentioned by Duerden (1902), who pointed out that spermaria have never been found alone but always in association with a large number of ova, while in a considerable number of coral species only ova were found. In Stylophora pistillata, egg development lasts approximately 6 months (July to December), while the development of male gonads takes only three months (October to December). It is possible, therefore, that a single collection of corals (as sampled by investigators in the past) increases the probability of finding colonies with female gonads only.

\section{Male Gonads}

Very few studies describe male gonads of corals (Fowler, 1888; Duerden, 1902; Gardiner, 1902; Marshall and Stephenson, 1933). Only Marshall and Stephenson (1933) provide some detailed information on their structure, but almost nothing is known about their development. Spermatogenesis in Stylophora pistillata is very similar to that described in Alcyonaria (e. g. Hickson (1901): Alcyonium, Gohar (1948): Clavularia hamra, Gohar and Roushdy (1961): Heteroxenia fuscescens). In general, the development of spermaria begins with a premordial gonad bulging into the cavity. After successive division, testes develop from the gonadal periphery towards the center.

Stylophora pistillata testes are more complicated in structure than Alcyonaria testes. The male gonads of $S$. pistillata may consist of several lobes, each of which can represent a different developmental stage. In addition, the testes have a larger variablility in shape and one gonad can simultaneously develop in two mesentery-cavities and often bulge into the tentacles. Such a structure has not been found in Alcyonaria.

To date, nothing is known on the ultrastructure of coral sperm. Within the Anthozoa this has been studied only in some sea anemones (Hinch, 1974; Lyke and Robson, 1975). We also have no knowledge about the physiology of sperm and egg interaction in corals, and on the mode of fertilization.

\section{Female Gonads}

The egg structure of Stylophora pistillata is very similar to that of many other scleractinian corals (Wilson, 1888; Duerden, 1902; Marshall and Stephenson, 1933). All eggs described were reported to contain large amounts of reservoir materials. Eggs of different coral species vary in diameter. In corals with large polyps (usually massive forms), the maximal egg diameter reaches more than $300 \mu \mathrm{m}$. Egg diameters of corals with small polyps (usually branching species) are much smaller (Table 1 ).

Table 1 suggests that coral species with large polyps 
- e. g. Favia doreyensis, Lobophyllia sp., Symphyllia recta, and Coenopsammia willeyi, - have relatively large eggs which they expel into the water (non-brooding species) while corals with small polyps - such as Pocillopora damicornis, Stylophora pistillata and Seriatopora species (Shlesinger, Tel-Aviv University, personal communication) - have relatively small eggs and many of them are brooding species. Thus, most of the scleractinian corals recorded by Atoda (1953), which extrude planulae have small polyps; unfortunately, no information exists on the sizes of their eggs.

During the process of egg development in Stylophora pistillata, only one oocyte per gonad develops, while the rest of the oocytes disappear. Such sequence of oocyte development has not yet been reported in scleractinian corals. However, a similar oogenesis occurs in other coelenterates. In the gorgonian Muricea, female polyps start with about 40 to 50 oocytes but only 1 to 2 large eggs are shed (Grigg, 1970). In Hydrozoa, egg formation involves phagocytosis of the entire oogonia by growing oocytes. Several oocytes merge into a single oocyte in which one nucleus becomes the germinal vesicle. The other oocyte nuclei remain as 'shrinking cells' (Tardent, 1974). Shrinking cells were not found in eggs of $S$. pistillata, suggesting that the mechanism here might be somewhat different. If this is true, the successful oocyte might absorb nutrients not only from the surrounding endoderm cells (Gohar, 1948), but also through phagocytosis on the other oocytes.

The peculiar way of reducing the number of eggs in Stylophora pistillata suggest the need for reconsideration of reports on egg numbers in other small polyped species: In some Hawaiian reef corals Stimson (1976) reported large numbers of eggs per polyp. In Pavona explanulata he found 240 eggs per polyp (in 12 ovaries), in Pocillopora meandrina about 120 eggs (in 6 ovaries) per polyp. He also mentions that the number of eggs declines with egg size. While Stimson (1976) reports that the eggs of $P$. meandrina are as small as 30 $\mu \mathrm{m}$, Grigg (1976) measured well-developed $(100 \mu \mathrm{m})$ oocytes in the same species near Hawaii. It seems possible that what Stimson (1976) termed eggs were actually oocytes, and his number of ovaries indicates the final number of eggs per polyp. According to this terminology, in the Hawaiian corals studied, there are between 4 eggs (Montipora species) to 12 eggs per polyp (Porites lobata, P. compressa, Pavona explanulata). In the present study, we found that at a given time Stylophora pistillata rarely exceeds 5 eggs per polyp.

Reports on egg numbers in large polyped species are even more scarce. Marshall and Stephenson (1933) found 93 eggs in a transverse section through the fertile region of a Favia doreyensis polyp. In the Red Sea coral Favia favus we counted in a single section 45 eggs in one polyp; since probably not all the eggs were cut in the histological section, this is a minimum estimate. Unlike in Stylophora pistillata (Fig. 3: 1), this section did not show groups of oocytes in a single female gonad, suggesting that in $F$. favus probably all oocytes develop to mature eggs.

Although the information at hand is very incomplete, we suggest two alternative pathways of oogenesis in corals, which seem to depend on the structure and location of the female gonads and on the size of the polyps. In small polyped species (usually branching forms) the gonads bulge into the gastric cavity and there is a reduction in the number of eggs per polyp (up to approximately 20 eggs) through absorption or phagocytosis of oocytes. In large polyped species (usually massive forms), the gonads are situated within the mesenteries, most oocytes develop into eggs, and hence a large number of eggs are produced per polyp.

It seems that unlike coral species which liberate planulae, colonies with large egg numbers per polyp (such as Favia doreyensis and F. favus) may undergo external fertilization. Marshall and Stephenson (1933) examined 24 colonies of $F$. doreyensis about once a

Table 1. Maximal egg diameter in several scleractinian corals

\begin{tabular}{|llcl|}
\hline Coral species & Growth form & $\begin{array}{c}\text { Egg diameter } \\
(\mu \mathrm{mn})\end{array}$ & Reference \\
\hline Coenopsammia willeyi & massive & 450 & Gardiner (1900) \\
Favia doreyensis & massive & 374 & Marshall and Stephenson (1933) \\
Lobophyllia sp. & massive & 350 & Marshall and Stephenson (1933) \\
Symphyllia recta & massive & 335 & Marshall and Stephenson (1933) \\
Montipora sp. & encrusting & 280 & Stimson (1976) \\
Porites lobata & massive & 120 & Stimson (1976) \\
Porites compressa & branching & 120 & Stimson (1976) \\
Pocillopora damicornis & branching & 30 & Stimson (1976) \\
Pocillopora meandrina & branching & 30 & Stimson (1976) \\
Pocillopora meandrina & branching & 100 & Grigg (1976) \\
Stylophora pistillata & branching & 230 & This paper \\
\hline
\end{tabular}


month between August and the following June. Most of them had ripe gonads in early December, but gametes disappeared in early January. Since no planulae were ever seen, it is probable that eggs and sperm were released during December. In reviewing Marshall and Stephenson's (1933) data, Connell (1974) concludes that internal fertilization in this species seems less likely. In Favia favus, an abundant Red Sea coral (Loya and Slobodkin, 1971), Shlesinger (Tel Aviv University, personal communication) followed the development of eggs during two years by chiselling small pieces from large colonies and studying them under a binocular microscope; he never observed planula larvae. Plankton nets which were placed every month for one year over large $F$. favus colonies did not yield any planulae (Wolodarsky and Havkin, Tel Aviv University, personal communication). Observations on F. favus colonies in aquaria indicate that this species releases large numbers of pinkish-red eggs into the water.

Of the 10 coral species studied by Marshall and Stephenson (1933), planula-larvae were seen only in two: Porites haddoni and Pocillopora bulbosa. Stimson (1976) examined seven common Hawaiian reef corals from January to December and established that only two species, Pocillopora damicornis and Cyphastrea ocellina, released planulae in the laboratory. In all the other species he found ova in histological sections, but never observed any planulae. He also noted that planulating corals had the smallest number of eggs per polyp. In Enewetak atoll, Stimson (1978) reported that 7 of the 12 species examined release planulae (4 of these were pocilloporids). Atoda (1974a) mentioned his failure to obtain planulae from most coral species found around the Palao islands in spite of all his efforts to collect them, during about 4 years of work (10 species out of approximately 100 were found to produce planulae). The failure to find planulae in many coral species studied might be partly due to the fact that in many corals planulation may be restricted to short periods of the year and/or at descrete times of the lunar cycle, or influenced by some physical factors of the environment (Stimson, 1978). In addition, many corals expel gametes into the water and fertilization is external.

In his work on the reproduction of corals at Hawaii and Enewetak, Stimson (1978) concluded that the mode of reproduction may be related to the habitat, in that coral species which have released planulae are characteristic of shallow water environments such as reef flats, while most of the species which failed to planulate in captivity are not commonly found on reef flats. It should be noted, however, that the coral species examined by Stimson (1978) at Enewetak were all collected from 0 to $2 \mathrm{~m}$ depth (at low tides).
We like to suggest for further examination the hypothesis that coral species which develop gonads in their body cavities (usually branching forms or small polyped corals), reduce the number of eggs during oogenesis, have small eggs and brood planula-larvae, while coral species which develop gonads within their mesenteries (usually massive forms or large polyped corals), have numerous and large ova per polyp and expel eggs into the water. The relationship between polyp size, egg diameter and the problem of brooding will probably prove to be more complicated. For example small polyped corals, might be found to reduce the number of their eggs in the process of oogenesis but have relatively large eggs, in which case we would expect them to release eggs into the water (non-brooding species) and vice-versa.

\section{Planula-Larva}

In contrast to the lack of knowledge about the genital cells of scleractinian corals, a lot of information has accumulated in the literature dealing with coral planulae. To date, planula-larvae of about 25 coral species are known (see reviews by Duerden, 1902; Atoda, 1953; Harrigan, 1972). Stylophora pistillata planulae were studied in the past by Atoda (1947b) in the Palao Islands. Nevertheless, we find great differences between the planula-larvae of $S$. pistillata from the Red Sea and that described from Palao.

The mature planula of Stylophora pistillata from the Red Sea is highly developed in comparison with other coral planulae previously described, including $S$. pistillata planulae from Palao. All scleractinian planulae have certain external features in common (Harrigan, 1972). Hyman (1940) pointed out that the embryos of Scleractinia commonly develop to a typical Edwardsia stage, with 4 pairs of complete mesenteries, while most pass on to the Halcampoides stage with 6 pairs of complete septa. A mature extruded planula of S. pistillata usually possesses 6 pairs of complete septa. A similar number of complete septa was found only in Agaricia agaricites (Duerden, 1902) and A. fragilis (Mavor, 1915), while in the other coral species only 4 complete pairs or less were recorded (Atoda, 1953).

The unique structural features (Fig. 5: 1-4) we observed in the Red Sea Stylophora pistillata planulae ('filaments' and 'nodules') were not described in any other coral planulae, including $S$. pistillata planulae from Palao. We suggest that some of the nodules especially those at the aboral part - serve as attachment organs. A similar function was described by Riemann-Zürneck (1975) in the larva of the sea anemone Choriactis laevis (Sagartiidae). The possible 
function of the filaments and the nodules near the oral pole is unknown.

Nutritive aspects in coral planulae remain to be investigated. Harrigan (1972) suggested that all coral planulae are lecithotrophic, not feeding until a variable length of time after settlement and metamorphosis. Our observations indicate that Stylophora pistillata planulae release zooxanthellae, mucus and unidentified lipid-like materials from their oral pole (Fig. 5: 5,6). The possibility that $S$. pistillata planulae are capable of 'swallowing' food particles through their 'mouthes' remains to be examined.

Stylophora pistillata planulae exhibit green fluorescence. Kawaguti (1973) suggests that the green fluorescence pigment in corals is a substance used to convert short-wave light into light useful for the zooxanthellae (for photosynthesis). The fluorescence of $S$. pistillata planulae in the Red Sea is the first record of this phenomenon in coral planulae.

The description of Stylophora pistillata planulae from Palao by Atoda (1947b) does not mention the existence of fluorescence in the planula, nor possible attachment organs, or expulsion of zooxanthellae, mucus and lipid-like granules through the mouth. There is a structural difference between the $S$. pistillata planula from Palao (consisting of 3 pairs of complete mesenteries) and the mature Red Sea planula (6 pairs of complete septa). It should be emphasized, however, that a great variability was recorded in the number of complete septa of the extruded Red Sea planulae, ranging from 0 to 6. In aquaria Atoda (1947b) found that $S$. pistillata planulae settled within 6 days after extrusion. Planulae which failed to settle died within 10 days. Our observations indicate that the majority of $S$. pistillata planulae settled within the first week of extrusion, but a considerable number of them continued to swim until a maximum period of 35 days. Breeding seasonality and the period of planulae extrusion also differ in Palao and the Red Sea populations of S. pistillata. The ecological implications of all these differences are discussed in the following paper (Rinkevich and Loya, 1979).

Acknowledgements. We wish to thank Prof. L. Fishelson and Dr. R. Grigg for their help and criticism. We are grateful to the M. B. L. staff at Eilat for their hospitality and facilities. Mr. A. Shoob photographed Fig. 5: 1-5. Special thanks are due to our friends Y. Benayahu and Y. Shlesinger for their enthusiastic help during the research.

This research was supported by an M. Sc. fellowship to B. Rinkevich by the Levi Eshkol Fund (Israeli Council for Research and Development) and by a research grant to Y Loya by the United States - Israel Binational Science Foundation (BSF) Jerusalem, Israel.

\section{LITERATURE CITED}

Atoda, K. (1947a). The larva and postlarval development of some reef building corals. I. Pocillopora damicornis cespitosa (Dana). Sci. Rep. Tôhoku Univ. (4th Ser.), 18, 24-47.

Atoda, K. (1947b). The larva and postlarval development of some reef building corals. II. Stylophora pistillata (Esper). Sci. Rep. Tôhoku Univ. (4th Ser.), 18, 48-64.

Atoda, K. (1953). The larva and postlarval development of the reef building coral. Sci. Rep. Tôhoku Univ. (4th Ser.), 20 , 105-121.

Campbell, R. D. (1974). Cnidaria. In A. C. Giese and J. S. Pearse (Eds), Reproduction of Marine Invertebrates, Vol. I. Academic Press, New York. pp. 133-199.

Connell, J. H. (1974). Population ecology of reef building corals. In O. A. Jones and R. Endean (Eds), Biology and Geology of Coral Reefs, 2. Academic Press, New York. pp. 205-245.

Duerden, J. E. (1902). West Indian madreporarian polyps. Mem. natn. Acad. Sci., 8, 402-597.

Fowler, G. H. (1888). The anatomy of the Madreporaria: III. $J$. microsc. Sci., 28, 17-34.

Gardiner, J. S. (1900). On the anatomy of a supposed new species of Coenopsammia from Lifu. Willey's Zool. Results, Cambridge, IV, 357-419.

Gardiner, J. S. (1902). Some notes on variation and protandry in Flabellum rubrum and senescence in the same and other corals. Proc Camb. phil. Soc biol. Sci., 11, 463-471.

Gohar, H. A. F. (1948). A description and some biological studies of a new alcyonarian species Clavularia hamra Gohar. Publs mar. biol. Stn. Ghardaqa, 6, 3-36.

Gohar, H. A. F. and Roushdy, H. M. (1961). On the embryology of the Xenidae (Alcyonaria). Publs mar, biol. Stn. Ghardaqa, 11, 45-72.

Grigg, R. W. (1970). Ecology and population dynamics of the gorgonians Muricea californica and Muricea fruticosa. Ph. D. thesis, University of California at San Diego.

Grigg, R. W. (1976). Fishery management of precious and stony corals in Hawaii. Sea Grant Tech. Rep., University of Hawaii, HIMB Contribution, 490, 1-48

Harrigan, J. F. (1972). The planula larva of Pocillopora damicornis: Lunar periodicity of swarming and substratum selection behavior. Ph. D. thesis, University of Hawaii.

Hickson, S. S. (1901). Alcyonium. L. M. B. C. Mem. typ. Br. mar. Pl. Anim., 5, 1-22.

Hinch, G. W. (1974). Comparative ultrastructure of cnidarian sperm. Am. Zool., 14, 457-465.

Hyman, L. H. (1940). The Invertebrates, I, Protozoa through Ctenophora, McGraw-Hill, New York.

Kawaguti, S. (1973). Electron microscopy on symbiotic algae in reef corals. Publs Seto mar. biol. Lab., 20, 779-783.

Loya, Y. (1972). Community structure and species diversity of hermatypic corals at Eilat, Red Sea. Mar. Biol., 13, $100-123$.

Loya, Y. (1976a). The Red Sea coral Stylophora pistillata is an r strategist. Nature, Lond., 259, 478-480.

Loya, Y. (1976b). Settlement, mortality and recruitment of a Red Sea scleractinian coral population. In G. O. Mackie (Ed.), Coelenterate Ecology and Behavior. Plenum Press, New York. pp. 89-100

Loya, Y. (1976c). Skeletal regeneration in a Red Sea scleractinian coral population. Nature, Lond., 261, 490-491.

Loya, Y. and Slobodkin, L. B. (1971). The coral reefs of Eilat (Gulf of Eilat, Red Sea). Symp. zool. Soc. Lond., 28, $117-139$.

Lyke, E. B. and Robson, E. A. (1975). Spermatogenesis in 
Anthozoa: Differentiation of the spermatid. Cell Tiss. Res. $157,185-205$

Marshall, S. M. and Stephenson, T. A. (1933). The breeding of reef animals. Part I. The corals. Scient. Rep. Gt Barrier Reef Exped., 3, 219-245.

Mavor, J. W. (1915). On the development of the coral Agaricia fragilis Danna. Proc. Am. Acad. Arts Sci., 51, 485-511

Riemann-Zurneck, K. (1975). Actiniaria des Südwestatlantik. II. Sagartiidae und Metridiidae. Helgoländer wiss. Meeresunters., 27, 70-95.

Rinkevich, B. and Loya, Y. (1977). Harmful effects of chronic oil pollution on a Red Sea scleractinian coral population. In Proceedings of the 3rd International Coral Reef Symposium, Miami, Florida, 2 (Geology), 586-591.

Rinkevich, B. and Loya, Y. (1979). The reproduction of the Red
Sea coral Stylophora pistillata. II. Synchronization in breeding and seasonality of planulae shedding. Mar. Ecol. Prog. Ser., 1, 145-152.

Stimson, J. S. (1976). Reproduction of some common Hawaiian reef corals. In G. O. Mackie (Ed.), Coelenterate Ecology and Behavior. Plenum Press, New York. pp. $271-279$.

Stimson, J. S. (1978). Mode and timing of reproduction in some common hermatypic corals of Hawaii and Enewetak. Mar. Biol., 48, 173-184.

Tardent, P. (1974). Gametogenesis in the genus Hydra. Am. Zool., 14, 447-456.

Wilson, H. V (1888). On the development of Manicina areolata. J. morph., 2, 191-252.

This paper was submitted to the editor ${ }_{i}$ it was accepted for printing on May 29, 1979. 